\title{
Myopathy in Autoimmune Diseases - Primary Sjögren's Syndrome and Dermatomyositis
}

\author{
Fumio Kaneko ${ }^{1,2, *}$, Ari Togashi², Erika Nomura ${ }^{2}$, \\ Teiji Yamamoto ${ }^{3}$ and Hideo Sakuma ${ }^{4}$ \\ 1 Institute of Dermat-Immunology and Allergy, \\ Southern TOHOKU Research Institute for Neuroscience \\ ${ }^{2}$ Dermatology, Southern TOHOKU General Hospital, \\ ${ }^{3}$ Neurological Institute, Southern TOHOKU Research Institute for Neuroscience \\ 4Pathology Department, Southern TOHOKU Research Institute for Neuroscience
}

Japan

\section{Introduction}

Myopathy, which clinically shows muscular pain (myalgia), weakness, cramps, stiffness and spasm, is one of neuromuscular disorders due to inflammation and/or dysfunction of muscle fibers. "Myositis", which is a general term for inflammation of the muscle, is pathologically an inflammatory myopathy seen seen mainly in autoimmune disorders including dermatomyositis (DM). The myopathy is classified by National Institute of Neurological Disorders and Stroke (NINDS) as indicated in Table 1 (1). We here focus myopathy on primary Sjögren's syndrome (pSjS) associated with myalgia "mimicking $\mathrm{DM}^{\prime \prime}$, as previously reported (2), and the inflammatory myopathy of DM (Table 2). Most of SjS is a secondary disorder to systemic autoimmune diseases including systemic lupus erythematosus (SLE), systemic sclerosis, DM, and so on. However, SjS, which is not associated with other autoimmune diseases, is considered to be an idiopathic primary disorder characterized by sicca symptoms. It is known that pSjS may be associated with fever, fatigue, myalgia, arthralgia, cutaneous vasculitis, etc. in addition to sicca symptoms (4-8).

$\mathrm{DM}$ is also characterized by myalgia, muscular weakness and fatigue due to inflammatory myopathy that ultimately progresses to muscle degeneration and the cutaneous involvements. The skin manifestations include helio-trope-like colored erythema and swelling on the eye-lids, cheeks, neck and upper extremities of the sun-exposed areas and Gottron's papules on the dorsa of the hand fingers (3). Although the etiology of DM remains unknown, internal maligmant disorders including lung and/or other organ cancers are frequently associated. Generally DM is classified as shown in Table 3 (9).

* Corresponding Author 
Congenital myopathies: characterized by developmental delays in motor skills; skeletal and facial abnormalities are occationally evident at birth

Muscular dystrophies: caused by progressive weakness in voluntary muscles; sometimes evident at birth

Mitochondrial myopathies: caused by genetic abnormalities in mitochondria, cellular structures that control energy; include Kearns-Sayre syndrome,

Glycogen storage diseases of muscle: caused by mutations in genes controlling enzymes that metabolize glycogen and glucose (blood sugar); include Pompe's, Anderson's and Cori's disease

Myoglobulinurias: caused by disorders in the metabolisum of a fuel (myoglobulin) necessary for muscle work; include McArdle, Tarui and DiMauro diseases

Dermatomyositis: an inflammatory myopathy and skin lesions

Myositis ossificans: characterized by bone growing in muscle tissue

Familiar periodic paralysis: characterized by episodes of weakness in arms and legs

Polymyositis inclusion body myositis and related myopathies: inflammatory myopathies of skeletal muscles

Neuromyotonia: characterized by alternating episodes of twiching and stiffness

Stiff-man syndrome: characterized by episodes of rigidity and reflex spasms

Common muscular cramps and stiffness and tetany: characterized by prologed spasms of the arms and legs

(National Institute of Neurological Disorders and Stroke, National Institutes of Health, USA ${ }^{1}$ )

Table 1. Classification of myopathy

\begin{tabular}{|c|c|c|c|c|c|c|c|c|c|}
\hline Patient & Gender & $\begin{array}{c}\text { Age } \\
\text { years }\end{array}$ & Disease & Enzyme & $\begin{array}{l}\text { Muscle } \\
\text { biopsy }\end{array}$ & $\begin{array}{c}\text { Auto- } \\
\text { antibody }\end{array}$ & $\begin{array}{c}\text { Observation } \\
\text { term }\end{array}$ & $\begin{array}{l}\text { Compli- } \\
\text { cation }\end{array}$ & Outcome \\
\hline 1. & F & 37 & pSjS & $\begin{array}{c}\text { No } \\
\text { abnormatities }\end{array}$ & myopathy & $\begin{array}{l}\text { ANA nv } \\
\text { SSA } 61.4 \\
\text { SSB } 21.6 \\
\end{array}$ & $3.0 \mathrm{y}$ & no & remission \\
\hline 2. & M & 32 & pSjS & $\begin{array}{c}\text { CK } 147 \\
\text { ALD } 5.8\end{array}$ & myopathy & $\begin{array}{l}\text { ANA } 20 \\
\text { SSB } 15.7\end{array}$ & $8 \mathrm{~m}$ & no & remission \\
\hline 3. & F & 29 & DM & $\begin{array}{c}\text { CK } 883 \\
\text { ALD } 11.2 \\
\end{array}$ & myositis & nv & $2.6 \mathrm{y}$ & no & remission \\
\hline 4. & F & 42 & DM & $\begin{array}{c}\text { CK } 212 \\
\text { KL-6 } 2485\end{array}$ & nd & nv & $4.3 \mathrm{y}$ & $\begin{array}{l}\text { intestinal } \\
\text { peumonia }\end{array}$ & remission \\
\hline 5. & M & 45 & DM & $\begin{array}{c}\text { CK } 302 \\
\text { ALD } 8.4 \\
\end{array}$ & myositis & nv & $3.8 \mathrm{y}$ & no & remission \\
\hline 6. & $\mathrm{~F}$ & 55 & DM & SLD 5.7 & nd & nv & $3.11 \mathrm{y}$ & no & remission \\
\hline 7. & $\mathrm{~F}$ & 60 & DM & CK 364 & nd & nv & $2.0 \mathrm{y}$ & no & remission \\
\hline 8. & M & 66 & $\mathrm{DM}$ & $\begin{array}{c}\text { CK } 1706 \\
\text { ALD } 8.2 \\
\text { KL-6 } 1876 \\
\text { myoglobin } \\
29.7\end{array}$ & myositis & ANA 20 & $2.0 \mathrm{y}$ & $\begin{array}{l}\text { pneumonia } \\
\text { and cancer }\end{array}$ & death \\
\hline
\end{tabular}

ALD: aldolase, ANA: anti-nuclear antibody, CK: creatine kinase, DM: dermatomyositis,

F: female, M: male, nd: not done, Nv: negative, pSjS: primary Sjögren's syndrome,

SSA: anti-SjS A antibody, SSB: anti-SjS B antibody

Myopathy: non-inflammatory myopathy, Myositis: inflammatory myopathy

Table 2. Myopathy and myositis in primary Sjögren's syndrome (pSjS) and dermatomyositis (DM) 


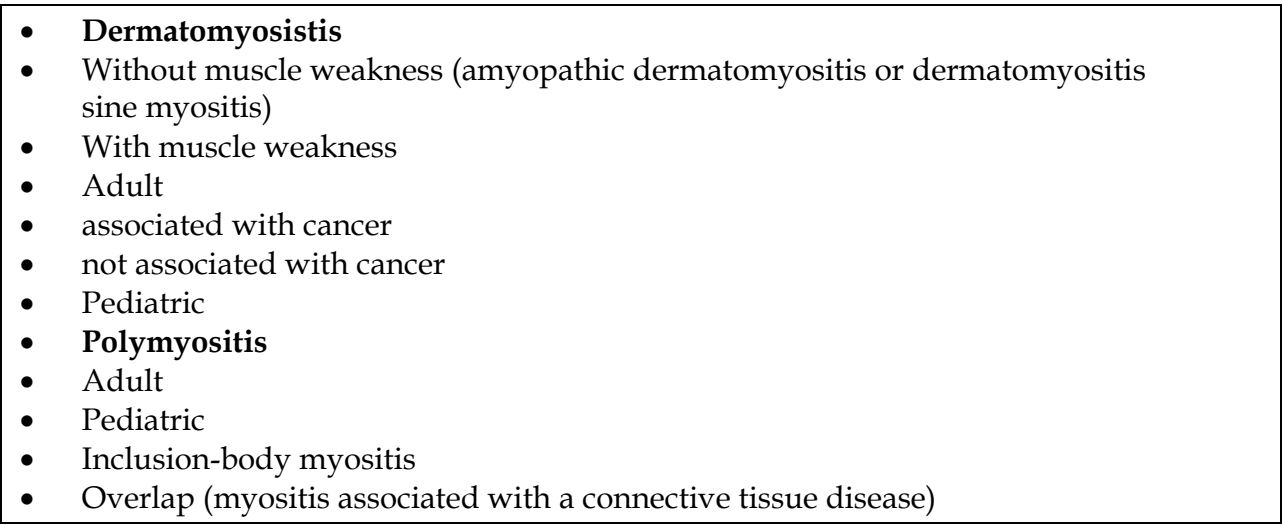

Drake LA, et al $^{9}$.: Guidelines of care of dermatomyositis. J Am Acard Dermatol 1996; 34: 824

Table 3. Classification of Dermatomyositis/ Polymyositis

\section{Cases}

pSjS: A 37-year-old woman (Case 1 in Table 2) was suffered from fever around $37.5^{\circ} \mathrm{C}$, fatigue, proximal muscle pain and weakness in her limbs and arthralgia since a week before her visiting our hospital. She presented herself with swelling and helio-trope-like colored erythema on the eye-lids (Fig. 1a,b), purpurish erythema-spots on the elbows, thin-reddish erythema patches on the legs (Fig.1c) and red palms. On the dorsa of the hand-fingers, the eruption looked like Gottron's papules was seen and thin purpuric spots were also noted on the paronychial areas. The electromyography showed low amplitude motor units (less than $1 \mathrm{mV}$ ) from muscles of the upper extremities that were suggestive myopathy. We suspected the patient had DM and the skin biopsy was taken from the erythematous patches on the left leg. The histology revealed so-called "lymphocytic vasculitis" which showed swollen

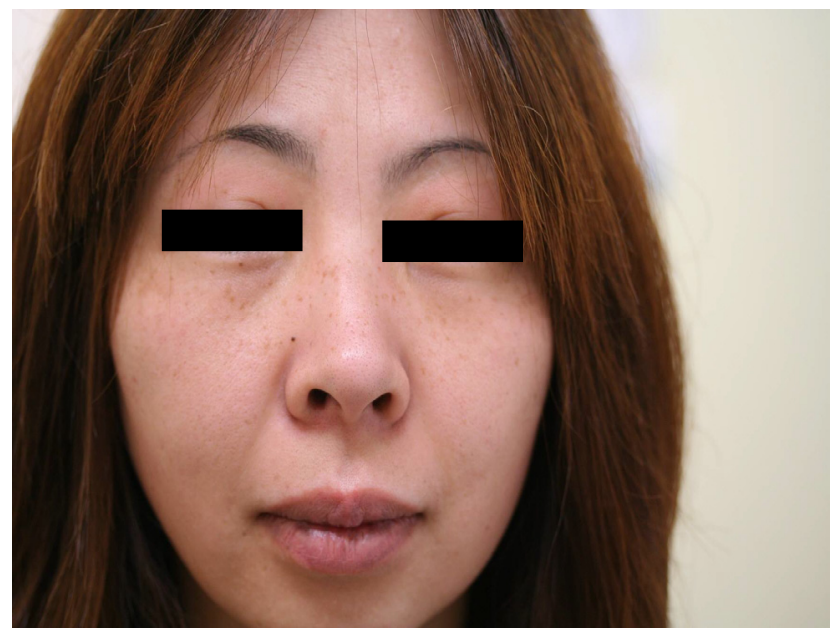

a) 


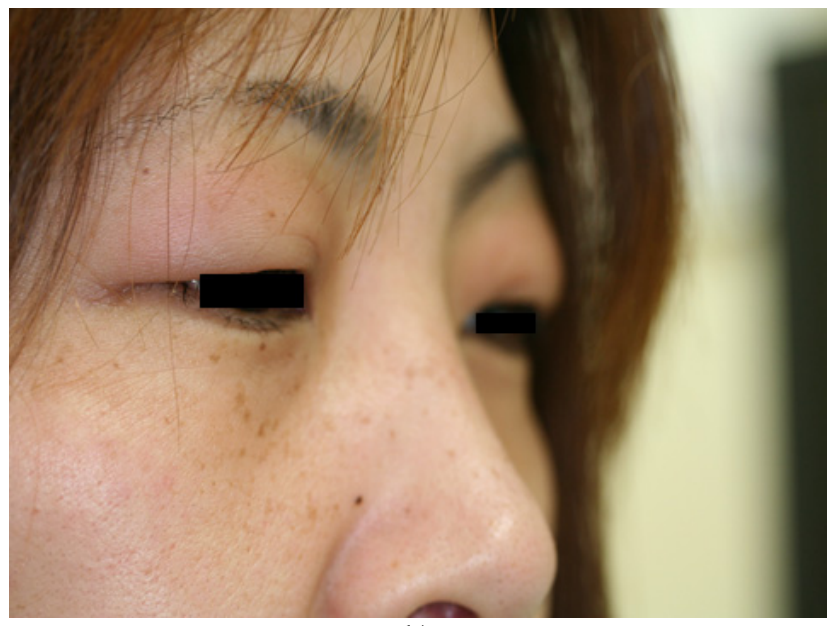

b)

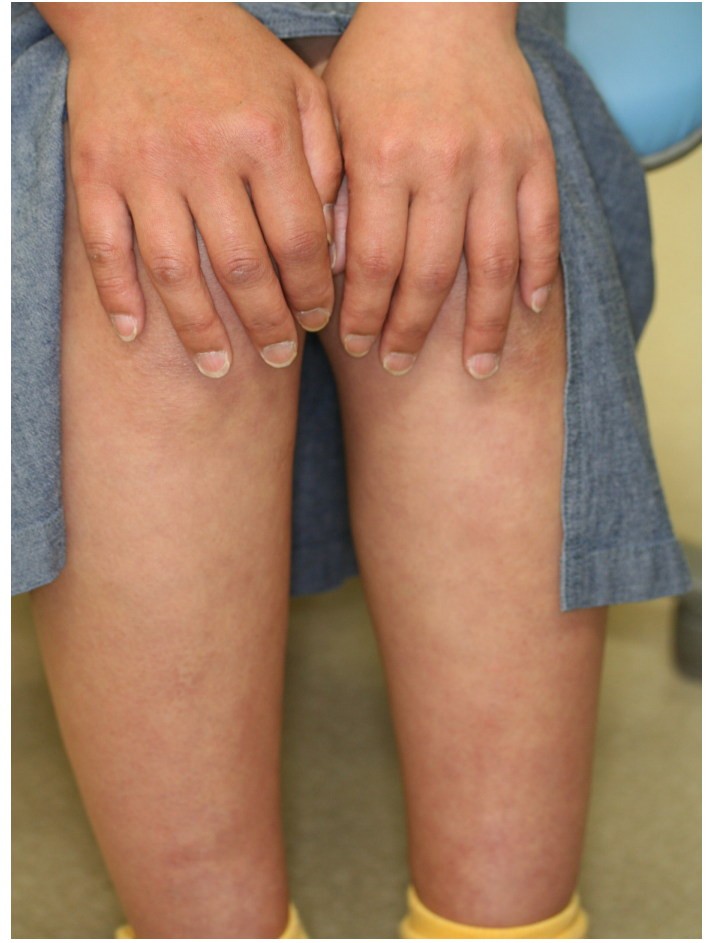

c)

Fig. 1. a,b) Close-up view of the right upper eye-lid showing slightly swollen and heliotrope-like colored erythema (Case 1 in Table 2). c) Gottron's nodule-like eruption on the dorsa of the fingers and thin-reddish erythematous patches on the lower legs. 
vascular walls surrounded by mainly monocytes and a few of neutrophils in the middle and deep dermis (Fig. 2a,b). No deposit of IgG, IgA, IgM and C3 was seen at the dermoepidermal (D-E) junction and vascular walls in the dermis by immunofluorescent microscopy. The immunochemical histology revealed $\mathrm{CD} 4^{+}>\mathrm{CD} 8^{+}>\mathrm{CD} 56^{+}$cells distributed around vessels in the deep dermis. A muscle biopsy was performed from the biceps muscle of the left-upper arm where the patient was complaining of pain. No features of inflammation associated the "muscle fiber degeneration" could be found though slight vascular infiltration was seen in the interstitial tissue.

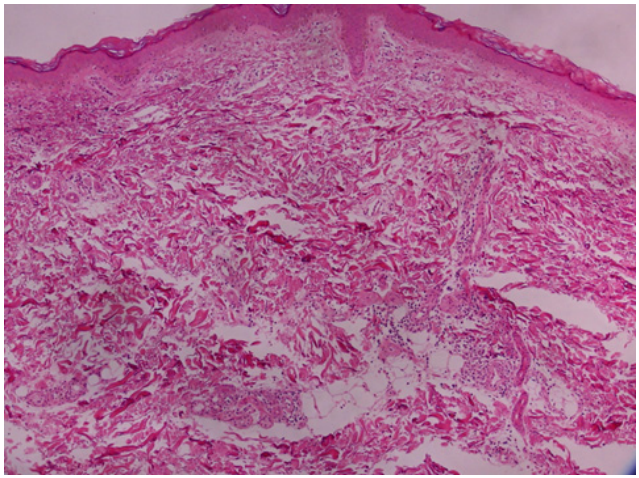

a)

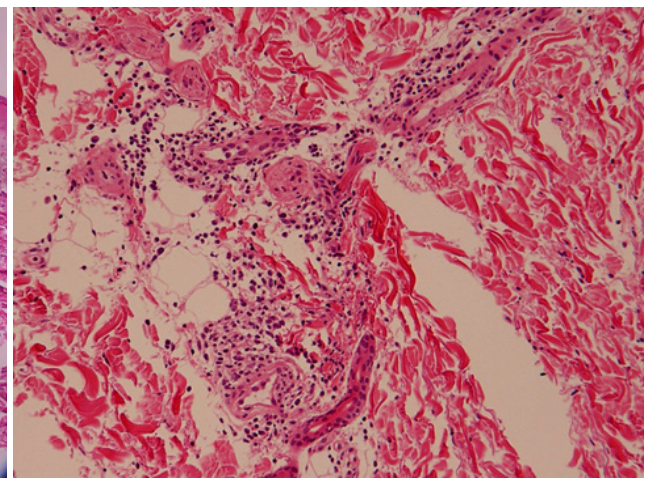

b)

Fig. 2. a) A skin biopsy from the left side of the lower leg revealed, a. vascular infiltration with lymphoid cells and a few neutrophils in the middle and deep dermis (H\&E stain, x40). b) The magnified view showed swelling of the vascular endothelial cells with slight degeneration infiltrated by lymphoid cells, suggesting so-called "lymphocytic vasculitis" (x 200)

Laboratory examinations revealed within normal-limit (WNL) ranges of white blood cells (WBC), red blood cells (RBC) and serum AST (aspartate aminotransferase), ALT (alanine aminotransferase), and CK (creatine kinase) (28 IU/L, WNL: 48 259) and aldolase (ALD) (2.2 IU/L, WNL: 2.5 5.6) were rather lower than WNL. The serum levels of complement were high in CH50 (58.4 u/ml, WNL: 31.0 48.0) but levels of C3 and C4 were WNL. Although auto-antibodies (auto-Abs) including anti-nuclear Ab (ANA), anti-Jo-1, anti-DNA and anti-acetylcholine receptor Abs and RA factor were negative, anti-Sjögren's syndrome A (anti-SSA) and anti-SSB Abs showed the titers of 61.4 and 21.6 (WNL: less than 1.0), respectively, which were highly positive in detection by ELISA. Serum carcinoembryonic antigen (CEA) was not detected. Urinalysis revealed no abnormalities except detection of acetone body. The chest X-ray and positron emission tomography (PET) with 18FDG (2deoxy-2-fluoro-D-glucose) were performed but no abnormal uptakes were detected except for an enlarged lymphnode at the right-side neck and slight enlargement of the liver and spleen. Ophthalmological examinations revealed positive Schirmer's test $(10 \mathrm{~mm} / 6 \mathrm{~mm})$ and fluorescein test which showed dry-eyes, although the amount of saliva was $3.5 \mathrm{ml} / 10 \mathrm{~min}$ which seemed to be low But WNL. The pain of visual analog scale (VAS) score was $75 \mathrm{~mm}$ when she initially visited our clinic.

The patient was diagnosed as having pSjS with myalgia mimicking DM, which may be classified as the extraglandular type. She was treated with prednisolone (PSL) $20 \mathrm{mg} /$ day and non-steroidal anti-inflammatory drugs (NSAIDs). The symptoms including the 
cutaneous manifestations completely disappeared and pain VAS score also gradually decreased to $55 \mathrm{~mm}$ in a week. The patient was quickly recovered from fatigue, subfebrile state, myalgia and arthralgia two weeks after treatment by oral steroid. However, PSL administration of within $10 \mathrm{mg}$ /day was needed to keep her well condition, although more than two years have been passed since her first visit.

Although the other 32 year-old male patient (Case 2) complained of dry eyes, mild fever, myalgia and muscle weakness of the upper extremities for more than one year, we initially suspected DM and examined for possibility of his having SjS regardless of absence of a DMlike eruption. Ophthalmologically he was suggested to have SjS. The blood examination revealed ALT $40 \mathrm{U} / \mathrm{L}$ (WNL: 6-36), ALD $5.8 \mathrm{IU} / \mathrm{L}$, titers of ANA 20x (speckled type) and anti-SSA Ab 15.7 which were relatively high. However, a biopsy from the biceps muscle of the left upper arm was free from inflammation, and no internal malignancy was associated through examinations including PET with ${ }^{18 F D G}$. He has been followed as pSjS similarly to the Case 1 for the duration of more than half a year.

DM: A 29 year-old female (Case 3) visited our clinic for helio-trope-like eruptions on the sun-exposed areas including upper eye-lids, cheeks and V-neck area (Fig. 3a), swollen fingers with periungual hemorrhage of the hands (Fig. 3b) and myalgia of the upper extremities. The examination revealed a rise of AST and ALT (65 and 46 U/L; WNL: 35-11 and 39-6, respectively), CK $883 \mathrm{U} / \mathrm{L}$ and ADL $11.2 \mathrm{IU} / \mathrm{L}$, but no auto-Abs including ANA, anti- SSA and SSB Abs were found. No internal malignancies were found. However, a biopsy from left biceps muscle revealed the typical myositis with intersititial vascular infiltration (Fig. 4a). The immunochemistry of infiltrated cells around the interstitial vessels of the muscle tissue revealed CD4 $4^{+}>\mathrm{CD} 8^{+}>\mathrm{CD} 68^{+}$cells and little of $\mathrm{CD} 20^{+}$cells as similarly seen in the cutaneous findings of Case 1 (Fig. $4 \mathrm{~b}$ ). We made a diagnosis of early stage of DM.

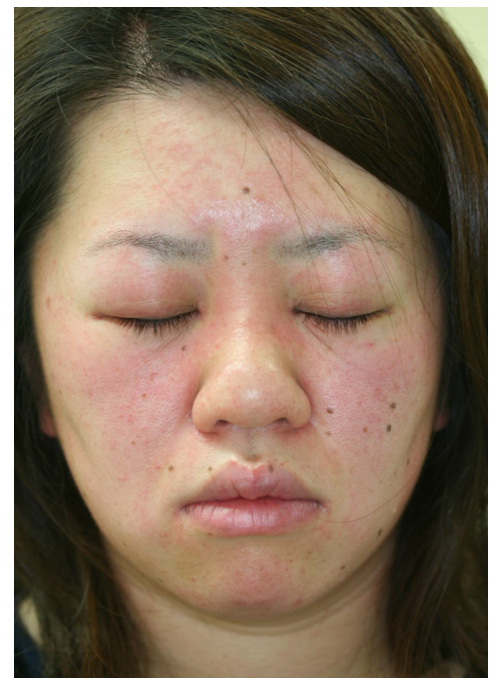

a)

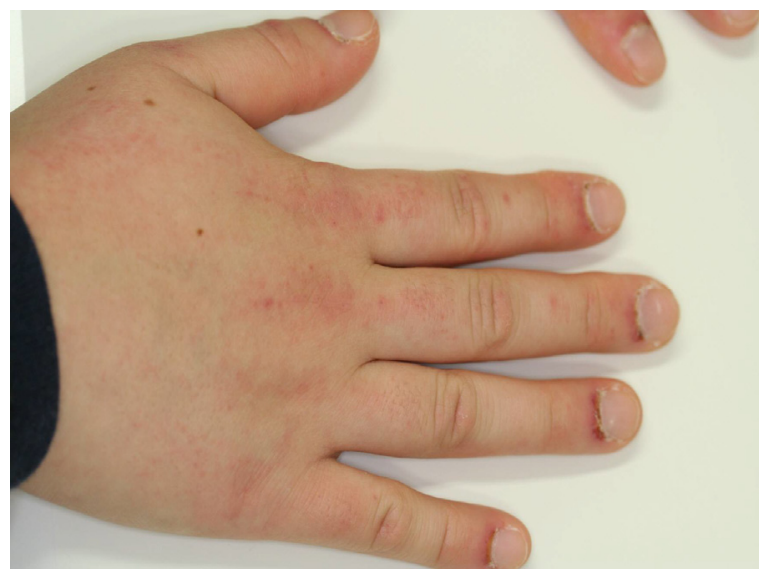

b)

Fig. 3. a) A 29 year-old female with dermatomyositis (DM) (Case 3). Swollen helio-trope-like erthema on the upper eye-lids and cheeks. b) Swollen erythema on the dorsa of the hands and periungual hamorrhage of the fingers. 


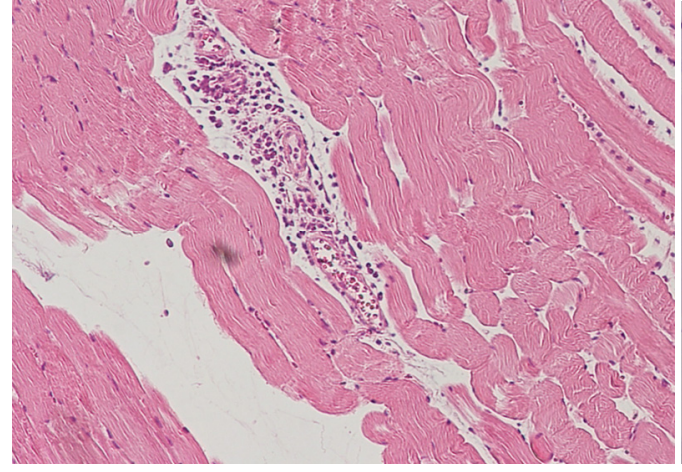

a)

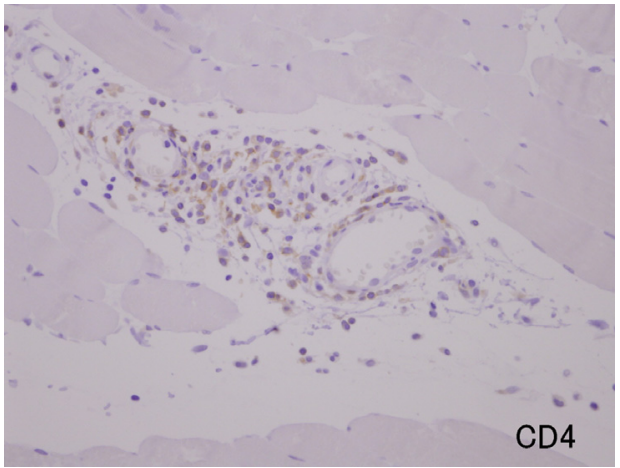

b)

Fig. 4. a) A biopsy specimen of muscle tissue from the left biceps muscle of patient with dermatomyositis (DM) (Case 3). Lymphoid cell infiltration around the vessels was found in the interstitial tissue (HE, 200x). b) Immunohistology of CD4 ${ }^{+} \mathrm{T}$ cells in the interstitial perivascular infiltration of the biceps muscle (Avidin-biotin stain, 20x). The infiltrated cells are $\mathrm{CD} 4^{+}>\mathrm{CD} 8^{+}>\mathrm{CD} 56^{+}$mononuclear cells.

A 66 years old man (Case 8) was referred to our clinic for sudden episode of helio-tropelike colored erythematous eruption on the sun-exposed areas including the face, V-neck area, upper back and upper extremities associated with "myopathy" exhibiting muscle weakness and myalgia (Fig. 5). The patient had heavily smoked cigarettes a pack or more a day. He was initially suspected to have photosensitive dermatitis due to some photosensitizer and/ or DM and the examinations including skin and muscle biopsy from left-upper arm were performed. Laboratory examinations revealed WBC 11,070 / $\mu$ l, RBC $327 \times 10^{4} / \mu 1$, CRP $14.28 \mathrm{mg} / \mathrm{dL}$ (WNL: 0.30), WNL of serum transaminases (AST and ALT), high levels of CK 1,706 U/L (WNL: 259-2.5) , ALD 8.2 IU/L (WNL: 5.6-2.5), myoglobulin-U $29.7 \mathrm{ng} / \mathrm{mg}$ (WNL: 10 0) and KL-6 $1876 \mathrm{U} / \mathrm{mL}$ (WNL: 499-0). The titers of auto-Abs showed WNL as to anti-DNA, anti-Jo-1, anti-RNP, Sm, and anti-SSA and antiSSB Abs except for ANA 20x (speckled type). Although CEA, CA15-3, AFP-L3, -L2,-L2, 3 and CA602 were negative, we suspected the patient might have an association with lung carcinoma after the chest X-ray and CT examination. The skin histology of the helio-tropelike erythema revealed as SLE-like findings exhibiting liquefaction degeneration of the DE junction and edema of the upper dermis with a little lymphoid cell infiltration (Fig. 6) and immunohistologically, IgG, IgM and complement C3 were linearly deposited at the D-E junction. The muscle biopsy from the biceps of the left arm exhibiting myalgia shows a tiny interstitial perivascular infiltration between the muscle bundles, suggesting "myositis", although obvious muscular-degeneration was not found. The symptoms of the skin rash and myalgia of the extemities were improved temporary after treatment with oral PSL and NSAIDs. However, the patient died by lung cancer 2 years after his first visit to our clinic. 


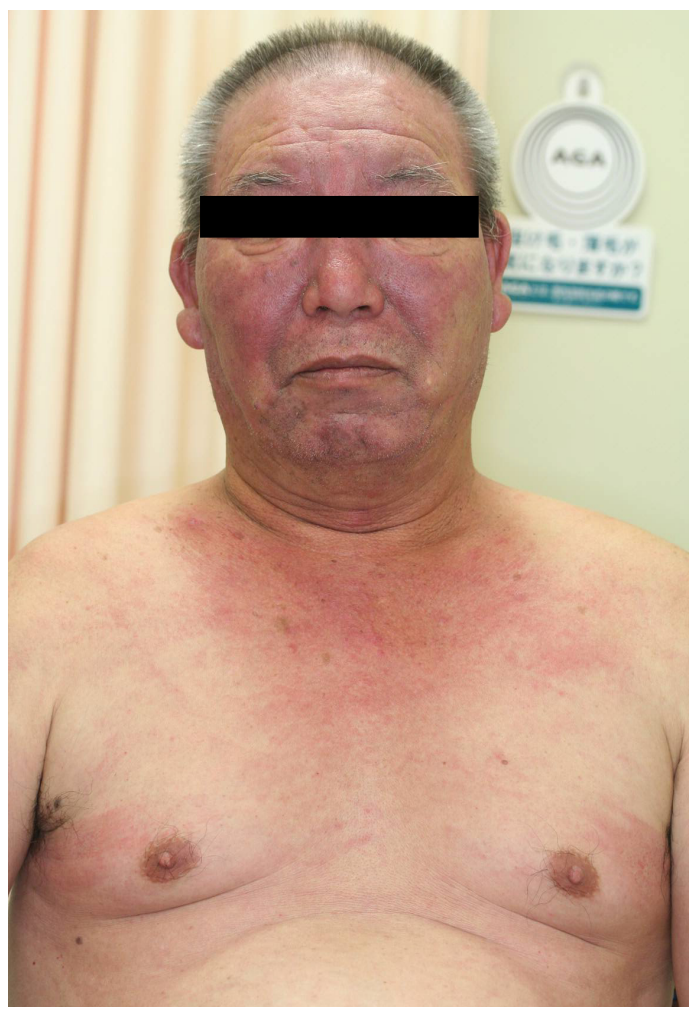

Fig. 5. A 66 years old patient with DM (Case 8) associated with lung cancer. Helio-trope-like erythema can be seen on the face and upper breast (so-called sun exposed areas).

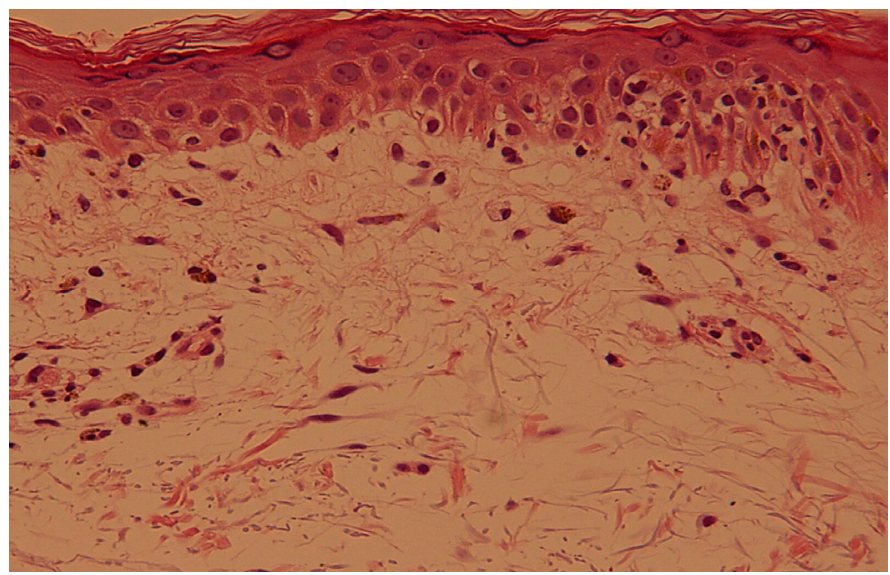

Fig. 6. A biopsy specimen of the helio-trope-like erythema from the upper chest. Liquefaction degeneration can be seen at the D-E junction and edema and a few lymphoid cell infiltration are present in the upper dermis (HE, 200x). 


\section{Discussion}

It is rare to see the cases of pSjS with myalgia in Japan, but about $30 \%$ of pSjS patients are reported to be associated with muscle involvement known as fibromyalgia in US and European countries $(5,6)$. The main cutaneous involvement is purpura, annular shaped erythema and/or macules, erythematous papules and ischemic ulcers due to microvasculitis in pSjS $(7,8)$. In this patient (Case 1 in Table 2), the cutaneous eruptions including the swollen and helio-trope-like colored erythema on the eye-lids, thin-reddish macules on the limbs, purpuric spots and Gottron's papule-like eruption on the dorsa of the fingers were recognized and quickly disappeared after administration with low dose of PSL. Although the clinical signs-like DM did not reappear by the treatment, the continuous treatment with PSL seems to be still needed. As reported that this disorder is a bothersome and slowly progressive disease (10-12), we should follow the clinical course whether the patient might develop lymphoproliferative disorders in a near future because the enlargement of the lymphnode and hepatosplenomegaly was noted initially. Regarding Case 2, the clinical symptoms and laboratory examination were suggestive of DM associated with SjS without the skin manifestations. We considered him as having pSjS associated with myopathy because dry-eye symptoms, positive anti-SSA Ab and no cutaneous symptom of DM were noted. Although these 2 cases of pSjS were associated with myalgia, the cause of their myopathy is not clear because no inflammation was found in the biopy specimens from their biceps muscle. However, it is reported that the myopathy might be due to small-vessel injury by auto-Abs or circulating immune complexes because electrondence deposits were noted (13). As to the infiltrated cells around the vessels in the cutaneous lesion, the CD4 $4^{+} \mathrm{T}$ cells were dominant as similar to the findings in myositis of patients with DM.

$\mathrm{DM}$ is an idiopathic inflammatory disorder characterized by inflammatory myopathy, indicating myositis, and skin manifestations and it can be associated with the secondary SjS sometimes. The etiology is still unknown and the prevalence is estimated as 1-10 cases per million population, but in children 3.2 cases per million which are distributed in the whole world (3). The clinical types of DM are classified in Table 3 and the internal malignancies are frequently associated in the adult type of DM. The risk is reported to be a 6.5-fold higher than ordinary persons after 45 years of age (14). Regarding myopathy in DM patients it might be characterized by inflammatory myopathy progressing to myositis and degeneration of muscle fibers, and the helio-trope-like eruptions on the sun-exposed areas showed SLE-like changes histologically. On the other hand, there are the cases associated without myogenic symptoms in DM, which is called as "amyopathic DM" (DM sine myositis). However, these cases should be considered as "pre-myopathic DM" because they might Be rather early diagnosed (15). Though the direct cause of myopathy is still unknown, there are some pathogeneses reported, such as the presences of myositis- specific auto-Abs $(15,16)$ and inflammatory cytokines from T cells including interleukin (IL)-17 and IL-23 in early stage of patients with DM (18). The study regarding Th1/Th2 balance showed that Th2 cell predominance was suggested in patients with active stage of DM (19). In plasma of patients with DM and/or polymyositis, microparticles derived from CD14+ mononuclear cells, $\mathrm{CD}^{+} \mathrm{T}$ cells and $\mathrm{CD} 19^{+} \mathrm{B}$ cells were found to be elevated by electron microscopic examination, which suggests these diseases were immunological disorders (20). It is reported that $\mathrm{CD} 19{ }^{+} \mathrm{CD} 23^{+}$cells are increased and that $\mathrm{CD} 4{ }^{+} \mathrm{CD} 45 \mathrm{RO}^{+}$cells are decreased in the peripheral blood of patients with DM, suggesting reduction of regulatory $\mathrm{T}$ cells (21). It 
was also suggested that $\mathrm{CD} 4{ }^{+} \mathrm{CD} 25^{+}$cells, forkhead/winged helix transcription factor (Fox $\mathrm{P3})^{+}$, transforming growth factor ${ }^{+}$and $\mathrm{IL}^{-10^{+}}$cells were reduced in peripheral blood of patients with DM (21). Actually, $\mathrm{CD} 4^{+} \mathrm{CD} 8^{+}$cells were significantly distributed around vessels in the interstitial tissues of the muscle bundles in our patients with DM. These cells might be $\mathrm{CD} 4{ }^{+} \mathrm{CD} 28^{+}$(null) cells and $\mathrm{CD} 8{ }^{+} \mathrm{CD} 28^{+}$(null) cell infiltration, as reported, and it is of interest that circulating $\mathrm{CD} 4{ }^{+} \mathrm{CD} 28^{+}$cells and $\mathrm{CD} 8^{+} \mathrm{CD} 28^{+}$cells were significantly increased in seropositive individuals, responded to human cytomegalovirus antigen stimulation and correlated with disease duration (22).

As to treatment for myopathy of patients with $\mathrm{pSjS}$ and DM, adequate doses of NSAIDs and/or oral steroids were mainly used in corresponding to their clinical severities and these were considered to be effective. However, in addition to these drugs, the combination with immunosuppressive agents such as azathioprine, cyclosporine, mycophenolate or methotrexate should be used for the autoimmune diseases, if they were not clinically controlled. The biological agent, rituximab, and tacrolimus may offer additional benefit to some patients and emerging agents against T cells, B cells, transmigration or transduction molecules may be discussed as New treatments (23).

\section{Conclusion}

Myopathies are neuromuscular disorders exhibiting myalgia and muscular weakness due to dysfunction of muscle fibers which are frequently seen in autoimmune diseases. We here discussed about the non-inflammatory myopathy seen in patients with pSjS and the inflammatory myopathy, that is myositis, found in patients with DM is suggested to be Immunological dysfunction in pathogenesis. Although the mechanism of the myopathy is still unclear, it might be due to inflammatory cytokines released from $\mathrm{CD} 4{ }^{+} \mathrm{CD} 28^{+}$(null) cells and $\mathrm{CD} 8{ }^{+} \mathrm{CD} 28^{+}$(null) cells infiltrated around vessels in the muscles of patients with MD.

\section{Abbreviations}

$\mathrm{Ab}$, antibody; ALD, aldolase; ANA, anti-nuclear antibody; anti-SSA Ab, anti- Sjögren's syndrome A Ab; anti-SSB Ab, anti- Sjögren's syndrome B Ab; CK, creatine kinase; D-E junction, dermo-epidermal junction; DM, dermatomyositis; IL, interleukin; NSAID, nonsteroidal anti-inflammatory drug; pSjS, primary Sjögren's syndrome; PSL, prednisolone; VAS, visual analog scale; WNL, within normal limit

\section{References}

[1] NINDS Myopathy Information Page: What is myopathy?, National Institute of Health, USA, December 10, 2010.

[2] Saito S, Togashi A, Kaneko F, Yamamoto T, Uchida T, Oyama N: Primary Sjögren's syndrome with myalgia mimicking dermatomyositis. J Dermatol 2010; 37: 837-839.

[3] Koler RA, Montemarano A: Dermatomyositis, Am Farm Physician 2001; 64: 1565-1573.

[4] Tishler M, Barak Y, Paran D, Yaron M. Sleep disturbances, fibromyalgia and primary Sjögren's syndrome. Clin Exp Rheumatol 1997; 15: 71-74.

[5] Pendarvis WT, Pillemer SR. Widespread pain and Sjögren's syndrome. J Rheumatol 2001; 28: 2657-2659. 
[6] Lindvall B, Bengtsson A, Ernerudh J, Eriksson P. Subclinical myositis is common in primary Sjögren's syndrome and is related to muscle pain. J Rheumatol 2002; 29: 7-7-25.

[7] Eriksson P, Andersson C, Ekerfelt C, et al. Sjögren's syndrome with myalgia associated with subnormal secretion of cytokines by peripheral blood mononuclear cells. J Rheumatol 2004; 31: 729-735.

[8] Ramos-Casals M, Anaya J-M, Garcia-Carrasco M, et al. Cutaneous vasculitis in primary Sjögren syndrome-classification and clinical significance of 52 patients. Medicine 2004; 83: 96-106.

[9] Drake LA, Dinehart SM, Farma ER, Goltz RW, Graham GF, Hordinski MK, et al.: Guidlines of care of dermatomyositis, J Am Acad Dermatol 1996; 34: 824-829.

[10] Molina R, Provost TT, Alexander EL. Two histopathologic prototypes of inflammatory vascular disease in Sjögren's syndrome: Differential association with seroactivity to rheumatoid factor and antibodies to Ro (SS-A) and with hypocomplementemia. Arthritis Rheum 1985; 28: 1251-1258.

[11] Theander E, Anderson SI, Manthorpe R, Jacobson LT. Proposed core set of outcome measures in patients with primary Sjögren's syndrome:5 year follow up. J Rheumatol 2005; 32: 1495-1502.

[12] Champey J, Corruble E, Gottenberg JE, et al. Quality of life and psychological status in patients with primary Sjögren's syndrome and sicca symptoms without autoimmune features. Arthritis Rheum 2006; 55: 451-457.

[13] Ringle SP, Forestot JZ, Tan EM, Wehling C, Griggs RC, Butcher D. Sjögren's syndrome and polymyositis or dermatomyosistis. Arch Neurol 1982; 39: 157-163.

[14] Airio A, Pukkala E, Isomaki H. Elevated cancer incidence in patients with dermatomyositis: a population based study. J Rheumatol 1995; 22: 1300-1303.

[15] Gerami P, Schope JM, McDonald L, Walling HW, Sontheimer RD. A systemic review of adult-onset clinically amyopathic dermatomyositis (dermatomyosistitis sine myositis): a missing link within the spectrum of the idiopathic inflammatory myopathies. J Am Acad Dermatol 2006; 54: 597-613.

[16] Mammen AL. Dermatomyositis and polymyositis: clinical presentation, autoantibodies and pathogenesis. Ann N Y Acad Soc 2010; Jan: 1184; 134-153.

[17] Gherardi RK. Pathogenic aspects of dermatomyositis and overlap myositis. Press Med 2011; Apr: 40: e209-218.

[18] Shen H, Xia L, Lu J, Xiao W. Interleukin-17 and interleukin-23 in patients with polymyositis and dermatomyositis. Scand J Rheumatol 2011; 40: 217-220.

[19] Ishii W, Matsuda M, Shimojima Y, Iyoh S, Sumida T, Ikeda S. Flow cytometric analysis of lymphocyte subpopulations and Th1/Th2 balance in patients with polymyositis and dermatomyositis. Internal Medicine 2008; 47: 1593-1599.

[20] Baka Z, Senolt L, Vencovsky J, Mann IT, Simon PS, Kiltel A, Buzas E, Nagy G. Increase serum concentration of immune cell derived microparticles in polymyosisitis/ dematomyositis. Immunol Lett 2010; 128: 124-130.

[21] Antiga E, Kretz CC, Klembt R, Massi D, Ruland V. Characterization of regulatory T cells in patients with dermatomyositis. J Autoimmun 2010; 35: 342-350. 
[22] Fasth AE, Dastmaich M, Rahbar A, Saiomonsson S, Pandya JM, Lindroos E, Nennesmo I, Malmberg KJ, Soderberg-Naucler C, Trollmo C, Lundberg IE, Malmstrom V. T cell infiltrates in the muscles of patients with dermatomyositis and polymyositis are dominated by CD28null T cells. J Immunol 2009; 183: 4792-4799.

[23] Dalakas MC. Immunotherapy of inflammatory myopathies: practical approach and future prospects. Curr Treat Options Neurol 2011; 13: 311-323. 
(C) 2012 The Author(s). Licensee IntechOpen. This is an open access article distributed under the terms of the Creative Commons Attribution 3.0 License, which permits unrestricted use, distribution, and reproduction in any medium, provided the original work is properly cited. 